\title{
Undiagnosed Risk of Obstructive Sleep Apnea in Obese Individuals in a Primary Health Care Context
}

\section{Risco de Apneia Obstrutiva do Sono Não Diagnosticada em Indivíduos Obesos no Contexto dos Cuidados de Saúde Primários}

Jaime Pimenta RIBEIRO $\rrbracket^{1}$, Adão ARAÚJO'1, Cláudia VIEIRA¹, Filipe VASCONCELOS ${ }^{1}$, Pedro Marques PINTO1, Benedita SEIXAS ${ }^{1}$, Bruno CERCA 1 , Isabel BORGES ${ }^{1}$

Acta Med Port 2020 Mar;33(3):161-165 - https://doi.org/10.20344/amp.12319

\section{ABSTRACT}

Introduction: Obstructive sleep apnea is a clinical entity that is associated with an increase in morbidity and mortality and it is estimated that it is significantly undiagnosed. The objective of this study was to assess the risk of undiagnosed obstructive sleep apneain obese individuals.

Material and Methods: A descriptive and analytical cross-sectional study; the risk of obstructive sleep apnea's was assessed over a period of 11 months by applying the STOP-Bang questionnaire to all individuals who attended a family health unit who were aged $\geq$ 18 years and had body mass index of $\geq 30 \mathrm{~kg} / \mathrm{m}^{2}$ and who had not yet been diagnosed with obstructive sleep apnea and agreed to participate; the risk of an undiagnosed moderate to severe obstructive sleep apnea was considered for any STOP-Bang score of $\geq 3$. Results: The risk of undiagnosed obstructive sleep apnea was assessed in 888 individuals ( $59.3 \%$ females) with an average age of $59.6 \pm 14.68$ years and a mean body mass index $33.6 \pm 3.43 \mathrm{~kg} / \mathrm{m}^{2}$; the mean STOP-Bang score was $3.5 \pm 1.74,70.9 \%$ scored $\geq 3$; the frequency of all STOP-Bang questionnaire parameters was higher $(p<0.004)$ within the group with score $\geq 3$.

Discussion: The studied population is one of the main strengths, since it is in obese people that the incidence of this disease is higher. There are some limitations related to this sample coming from a single family health unit, as well as the patients' follow-up being carried out throughout routine appointments for diseases that are closely related with obstructive sleep apnea.

Conclusion: The level of underdiagnosis of obstructive sleep apnea's in obese individuals can be significantly high and a large proportion of them may have the disease at a moderate to severe stage; Family Physicians can have a very important role in screening and diagnosis.

Keywords: Obesity; Portugal; Primary Health Care; Sleep Apnea, Obstructive/diagnosis; Surveys and Questionnaires

\section{RESUMO}

Introdução: A apneia obstrutiva do sono é uma entidade clínica que condiciona aumento da morbimortalidade e estima-se que exista um elevado subdiagnóstico. Foi objetivo deste estudo avaliar o risco de apneia obstrutiva do sono não diagnosticada em indivíduos obesos.

Material e Métodos: Estudo transversal descritivo e analítico; durante um período de 11 meses foi avaliado o risco de apneia obstrutiva do sono aplicando o questionário STOP-Bang a todos os indivíduos com idade $\geq 18$ anos e índice de massa corporal $\geq 30 \mathrm{~kg} / \mathrm{m}^{2} \mathrm{que}$ frequentaram uma unidade de saúde familiar, sem o diagnóstico de apneia obstrutiva do sono e que aceitaram participar; considerou-se risco de apneia obstrutiva do sono não diagnosticada para score STOP-Bang $\geq 3$.

Resultados: Foi avaliado o risco de apneia obstrutiva do sono não diagnosticada em 888 indivíduos (59,3\% do género feminino), com idade média de 59,6 \pm 14,68 anos e índice de massa corporal médio de 33,6 $\pm 3,43 \mathrm{~kg} / \mathrm{m}^{2}$; o score STOP-Bang médio foi de 3,5 $\pm 1,74,70,9 \%$ apresentaram score $\geq 3$; a frequência de todos os parâmetros do questionário STOP-Bang foi superior $(p<0,004)$ no grupo com score $\geq 3$.

Discussão: A população estudada é uma das principais forças, pois é nas pessoas obesas que a incidência dessa doença é maior. Existem algumas limitações relacionadas com a amostra ser de uma única unidade de saúde, bem como o seguimento dos pacientes ser por doenças relacionadas com a apneia obstrutiva do sono.

Conclusão: O subdiagnóstico da apneia obstrutiva do sono nos indivíduos obesos pode ser muito elevado e uma grande parte destes pode apresentar doença moderada a grave; os médicos de Medicina Geral e Familiar podem ter um papel muito importante no rastreio e diagnóstico.

Palavras-chave: Apneia Obstrutiva do Sono/diagnóstico; Cuidados de Saúde Primários; Inquéritos e Questionários; Obesidade; Portugal

\section{INTRODUCTION}

Obstructive sleep apnea (OSA) is a clinical entity characterized by recurrent episodes of apnea and/or hypopnea during sleep, it occurs due to the total or partial collapse of the upper airway tract, ${ }^{1,2}$ which is associated with an increase in morbidity and mortality related to cardiovascular and neurovascular diseases, metabolic disorders and neu-

rocognitive functions. It may also increase the risk of occupational and driving accidents, as well as decrease labor's productivity as a consequence of daytime sleepiness and impaired neurocognitive abilities. ${ }^{1,3-6}$

The main metric for diagnosing OSA is the apnea hypopnea index $(\mathrm{AHI})$. This reflects the number of significant

1. Unidade de Saúde Familiar Corgo. Agrupamento Centro de Saúde Douro I - Marão e Douro Norte. Administração Regional de Saúde do Norte. Vila Real. Portugal.

$\square$ Autor correspondente: Jaime Pimenta Ribeiro. jaime.pim.ribeiro@gmail.com

Recebido: 13 de maio de 2019 - Aceite: 26 de agosto de 2019 | Copyright @ Ordem dos Médicos 2020 
events recorded per hour of sleep and is measured during some form of polysomnography. Several definitions of hypopnea exist and can lead to different apnea-hypopnoea index scores between medical centres,,$^{2,7}$ although it is generally accepted that there is a breathing sleep-disorder when $\mathrm{AHI}$ is greater than five events per hour. ${ }^{4}$

The prevalence of this condition is high and it is thought to be highly underdiagnosed. ${ }^{1,8,9}$ A systematic review carried out in 2016 by Senaratna et $a^{R}$ shows a prevalence in the general population of $9 \%$ to $38 \%$. However, it is estimated that the proportion of patients not diagnosed with OSA may be around $80 \% .^{1,9,10}$ In a study of 2121 individuals from Switzerland, it was concluded that if the most recent definitions for respiratory events and diagnostic techniques are commonly used, it is possible to note that almost every individual had some degree of breathing sleep-disorder. ${ }^{4}$ In Portugal, the real prevalence of OSA is still unknown. ${ }^{11}$ One of the best documented risk factors for this disease is obesity, with a high prevalence of OSA in obese individuals, as well as, a high prevalence of obesity in individuals with OSA, even though OSA may also be common in non-obese individuals. , $^{1,12-14}$

The gold standard method of OSA is polysomnography. However, it is a method with very high associated costs and limited accessibility, ${ }^{9,15}$ especially in countries with limited resources such as Portugal. As such, screening methods are being developed with the goal of adequately identify individuals at higher risk of OSA. ${ }^{16,17}$ The STOP-Bang questionnaire (Chung et al, 2008) is one of the latest OSA risk screening tools, is simple, objective and easy to apply, and is translated and validated for the Portuguese population, both at the level of sleep clinics and primary health care (PHC); it has demonstrated a high performance in the stratification of patients with suspicion and diagnosis of OSA. ${ }^{10,18}$

Given the high underdiagnosis and the epidemiological link between OSA and obesity, as well as the high prevalence of obesity in Portugal, ${ }^{19}$ it is important to screen the risk of undiagnosed OSA in obese individuals, to be able to improve the diagnosis and treatment of this disease in this risk group, especially in the case of undiagnosed patients with moderate to severe disease.

\section{MATERIAL AND METHODS Type of study \\ Cross-sectional, descriptive and analytical}

\section{Participants and study design}

During an 11 month period, from February to December 2017 , all individuals aged $\geq 18$ years and body mass index $(B M I) \geq 30 \mathrm{~kg} / \mathrm{m}^{2}$ who attended the family health unit (FHU) were invited to take part in the study. Those who were already diagnosed and those who refused to participate or were unable to communicate were excluded.

In total, 983 individuals were invited, 72 (7.3\%) were excluded for already having the diagnosis of OSA and 23 (2.3\%) for not accepting to participate or for not being able to communicate.
The STOP-Bang questionnaire was applied to all individuals who agreed to participate and data on gender, age, cervical perimeter and BMI was collected, in order to obtain all the parameters of the STOP-Bang questionnaire ${ }^{18}$ and calculate the risk score; the researchers did not interfere in the participants' interpretation of the STOP-Bang questionnaire. The risk score was calculated using the sum of the "yes" answers (8 parameters), with each answer "yes" being equal to 1 point, totaling a minimum score of 0 and maximum of 8; undiagnosed OSA was considered when the risk score was $\geq 3$, moderate risk was considered when the risk scores was between 3 to 4 and high risk was considered when the risk score was $\geq 5 .^{9,10}$ The STOP-Bang score cutoff was set at 4 , because of better accuracy in the obese population, according with Chung et al.

The study was approved by the Ethics Committee of Northern Portugal's Regional Health Administration. Both the original author of the questionnaire (Chung et al 2008) and the team who translated and validated the translation for the Portuguese population (Reis et al 2015) gave permission to use the questionnaire (Appendix 1: https://www. actamedicaportuguesa.com/revista/index.php/amp/article/ view/12319/Appendix_01.pdf).

All individuals who agreed to participate provided written informed consent. The individuals who presented a risk of undiagnosed moderate to severe OSA, were referred to their family doctor, with their consent.

\section{Statistical analysis}

A descriptive and inferential analysis was performed using the SPPSS ${ }^{\circledR} 22.0$ software (Statistical Package for the Social Sciences). For the characterization of the continuous variables the mean was used as a measure of central tendency and the standard deviation as a measure of dispersion; the percentage / frequency and $95 \%$ confidence interval $(95 \% \mathrm{Cl})$ (calculated using bootstrapping) were used to characterize the categorical variables. For the comparisons between the no-risk group of undiagnosed OSA (score < 3 ) and the group with risk of undiagnosed moderate to severe OSA (score $\geq 3$ ) different statistical tests were used: student's t-test for means and chi-squared test for proportions, and the significance threshold was set at $p<0.004$ (determined through the Bonferroni adjustment for multiple comparisons).

\section{RESULTS}

The sample was obtained from 888 individuals, of whom $59.3 \%$ were female and $40.7 \%$ were male, with an average age of $59.6 \pm 14.68$ years and a mean BMI of $33.6 \pm 3.43$ $\mathrm{kg} / \mathrm{m}^{2}$. The mean STOP-Bang score was $3.5 \pm 1.74$, and the majority of the individuals had a score of $3(23.9 \%), 4$ $(19.3 \%)$ and $2(18.1 \%)$; the distribution of the frequency of individuals by STOP-Bang scores is detailed in Fig. 1.

The proportion of individuals with a STOP-Bang score $\geq 3$ (risk of undiagnosed moderate to severe OSA) was $70.9 \%$ (95\% Cl: $67.9 \%-73.9 \%), 43.1 \%$ had a score of 3 to 4 (intermediate risk) and $27.8 \%$ presented score $\geq 5$ (high 


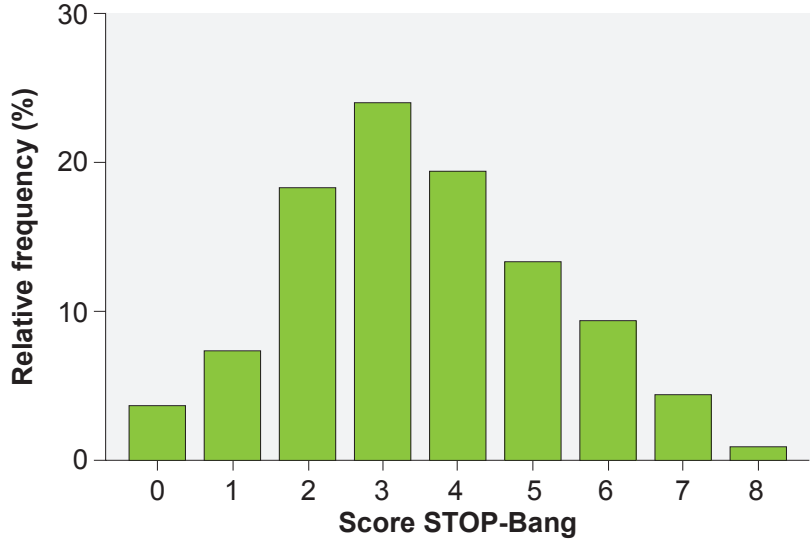

Figure 1 - Distribution of individuals according to the STOP-Bang questionnaire score

risk); within the group of individuals with STOP-Bang score $\geq 3$ (risk of undiagnosed moderate to severe OSA), $60.8 \%$ presented a score of 3 to 4 (intermediate risk) and $39.2 \%$ presented a score $\geq 5$ (high risk).

The proportion of individuals with a STOP-Bang score $\geq$ 4 was $47.1 \%$.

Table 1 shows the frequencies of the different parameters that make up the STOP-Bang questionnaire in relation to the total group of individuals, the group of individuals with score $<3$ and the group with score $\geq 3$; as well as the $p$-value of the statistical tests used for comparison between both groups. The frequency of all parameters in the comparison of individuals with score $<3$ and $\geq 3$ was higher in individuals with a STOP-Bang score $\geq 3$, with a statistically significant difference.

\section{DISCUSSION}

The proportion of adult obese individuals at risk of undiagnosed moderate to severe OSA was very high (about $70 \%$ ) and a significant portion, more than a quarter of the obese adult individuals, presented a high risk, represent- ing a group of individuals with probable undiagnosed moderate to severe disease and therefore untreated. All the parameters of the STOP-Bang questionnaire, including both those self-reported by individuals and those evaluated by researchers, were more frequent in the group with risk of undiagnosed moderate to severe OSA, and the minor differences were found in BMI, which may be related to the fact that all participants were obese (BMI $\geq 30 \mathrm{~kg} / \mathrm{m}^{2}$ ) even though the group of obese individuals at risk of undiagnosed moderate to severe OSA (score $\geq 3$ ) had slightly higher mean $\mathrm{BMI}$ and a higher proportion of obese individuals with a $\mathrm{BMI}>35 \mathrm{~kg} / \mathrm{m}^{2}$, which suggests that even among obese individuals, the higher degree of obesity may contribute to an increased risk of undiagnosed severity OSA.

In Portugal, the real prevalence of OSA is unknown. However, a cross-sectional study on the prevalence of known and diagnosed OSA at PHC level, carried out in 2014 within the framework of the Sentinel Physicians Network, estimated a prevalence of $0.89 \%$ in the population aged 25 years or older. ${ }^{11}$ This represents a very low estimate compared to international reports about the prevalence of this disease. ${ }^{1-3,8}$ This may be a sign of underdiagnosis, as the authors themselves point out in the article, which is in agreement with the high risk of undiagnosed OSA found in this study and the underdiagnosis estimates mentioned in the scientific literature, which refer to about $80 \%$ of OSA cases. ${ }^{1,9,10}$

According to Chung et al, a STOP-Bang score cutoff of 4 gives a better balance of specificity and sensitivity compared with the cutoff of 3 (the specificity is lower) in the obese population. ${ }^{9}$ Even so, the proportion of individuals with a STOP - Bang Score $\geq 4$ was $47.1 \%$, showing that almost half of individuals are at risk of undiagnosed moderate to severe OSA. However, the risk assessment tool validated for the Portuguese population and PHC only used the cutoff of 3 on the STOP-Bang score.

One of the strengths of this study is the fact that it has

Table 1 - Summary of the statistics of the sample studied and the comparison between groups of individuals with STOP-Bang score $<3$ and $\geq 3$

\begin{tabular}{|c|c|c|c|c|}
\hline & Total & Score $<3$ & Score $\geq 3$ & $\begin{array}{c}p \\
\text { (score }<3 \text { vs score } \geq 3 \text { ) }\end{array}$ \\
\hline n (\%) & 888 & $258(29.1 \%)$ & $630(70.9 \%)$ & \\
\hline Age (years) & $59.6 \pm 14.68$ & $52.2 \pm 16.68$ & $62.6 \pm 12.62$ & $<0.001^{*}$ \\
\hline BMI $\left(\mathrm{kg} / \mathrm{m}^{2}\right)$ & $33.6 \pm 3.43$ & $33.1 \pm 2.92$ & $33.8 \pm 3.6$ & $0.002^{*}$ \\
\hline $\mathbf{C P}(\mathrm{cm})$ & $39.2 \pm 3.76$ & $36.3 \pm 2.42$ & $40.4 \pm 3.57$ & $<0.001^{*}$ \\
\hline Snoring (\%) & $51.0 \%$ & $21.7 \%$ & $63.0 \%$ & $<0.001^{* *}$ \\
\hline Tiredness (\%) & $34.5 \%$ & $18.6 \%$ & $41.0 \%$ & $<0.001^{* *}$ \\
\hline Observed apnea (\%) & $23.5 \%$ & $1.2 \%$ & $32.7 \%$ & $<0.001^{* *}$ \\
\hline High BP (\%) & $68.9 \%$ & $37.6 \%$ & $81.7 \%$ & $<0.001^{* *}$ \\
\hline $\mathrm{BMI}>35$ kg/m² (\%) & $25.6 \%$ & $16.3 \%$ & $29.4 \%$ & $<0.001^{* *}$ \\
\hline Age $>50$ years $(\%)$ & $72.1 \%$ & $44.6 \%$ & $83.3 \%$ & $<0.001^{* *}$ \\
\hline $\mathrm{CP}>40 \mathrm{~cm}(\%)$ & $35.9 \%$ & $2.7 \%$ & $49.5 \%$ & $<0.001^{* *}$ \\
\hline Male (\%) & $40.7 \%$ & $7.4 \%$ & $54.3 \%$ & $<0.001^{* *}$ \\
\hline STOP-Bang score & $3.52 \pm 1.74$ & $1.5 \pm 0.71$ & $4.4 \pm 1.3$ & $<0.001^{*}$ \\
\hline
\end{tabular}

BMI: body mass index; CP: cervical perimeter; BP: blood pressure; ${ }^{t} t$-Student test; ${ }^{* *}$ chi-square test 
analyzed the risk of undiagnosed moderate to severe OSA in a group of individuals presenting one of the most well documented major risk factors for OSA such as obesity, whose prevalence in Portugal is very high, representing about $22 \%$ of the Portuguese population, ${ }^{19}$ which has been increasing and following the worldwide trends. ${ }^{20}$ The achieved sample size is quite large which allows for a good robustness to the results of the study. Another strong point is the fact that it used a risk assessment tool that has been translated and validated for the Portuguese population, both in the sleep clinic and in PHC. This risk assessment tool demonstrated a high performance in the stratification of patients with suspicion and diagnosis of OSA, with a high sensitivity and a high positive predictive value for OSA in patients with a STOP-Bang score $\geq 3$, as well as a high negative predictive value for OSA in patients with a STOPBang score $<3$, apart from allowing the categorization of the degree of risk, since this increases as the calculated score increases, in particular the risk of severe OSA. ${ }^{10,18,21}$

In terms of limitations, it should be noted that the study sample was a convenience sample and all participants were recruited in $\mathrm{PHC}$ which may introduce a selection bias, since these individuals may be attending PHCs units for having diseases that are closely related with OSA and which are given a lot of attention in $\mathrm{PHC}$, such as hypertension or diabetes mellitus, for example. This may lead to an overestimation of the risk of undiagnosed OSA in this group. Another limitation is the fact that only a single PHC unit population has been studied, and thus it is not possible to make an extrapolation of the results to the national population of obese individuals. The STOP-Bang questionnaire itself also presents a limitation regarding its specificity level for scores $\geq 3$ that is relatively low ( $53 \%$ according to Rebelo-Marques et al, 2018), but increases as the score calculated is higher, with specificity above $80 \%$ for scores of score $\geq 5$ and above $98 \%$ for scores ranging from 7 to $8 .{ }^{9,17,20}$

The high proportion of obese individuals at risk of undiagnosed moderate to severe OSA may be explained by several factors. Although the real prevalence of this disease is still unknown, it is estimated that it is high, as there are well-documented risk factors such as obesity. The medical community may not be aware of its real magnitude and this factor may be related to the high level of underdiagnosis. ${ }^{11}$

An internationally published review on OSA screening and assessment in PHC published in $2015^{22}$ concluded that the OSA screening model practiced in $\mathrm{PHC}$ is fragmented and ineffective and that many times PHC doctors find patients with OSA symptoms but do not apply the screening, nor assess the risk of OSA or instead refer to secondary care, which is what may be also occurring in Portugal. Other factors may also probably contribute, such as the fact that sometimes the individual experiences of daytime sleepiness are not valued neither reported to the doctor ${ }^{23}$; the inexistent clinical guidelines about this screening; PHC doctors deal with many chronic and acute problems in their daily appointments, limiting the time available for the implementation of screening; or the absence of a medical record module in the electronic health record to carry out this assessment and registration.

The application of a systematic, uniform, efficient and user-friendly screening method to stratify the risk of undiagnosed OSA such as the STOP-Bang questionnaire, ${ }^{16,21,24}$ in the main groups at risk for OSA, like those with obesity, hypertension or diabetes, may represent a very important improvement in the quality of patient assessment. Therefore, it would be possible to fight the insufficient response of secondary care, promoting the referral of patients with moderate to severe disease, in order to confirm the diagnosis, as well as to begin the appropriate treatment. An important impact on reducing morbidity and mortality of diseases closely correlated with $\mathrm{OSA}^{1,14}$ and its associated costs is expected. ${ }^{5}$

The results of this study help to fill the gap of the lack of knowledge of the prevalence by estimating the risk of undiagnosed OSA in obese individuals, although only the risk of disease has been assessed, through the application of a screening tool, and the diagnosis and real prevalence have not been confirmed. However, there is a need to extend this study in order to be able to reflect the national reality and to extend the study of the risk of undiagnosed OSA to other risk groups, so that the medical community, particularly $\mathrm{PHC}$ doctors, can become more aware of this problem. As such, it is important to carry out cost-effectiveness studies to establish standards of clinical guidelines addressed to groups at higher risk, allowing a reduction of underdiagnosis and the provision of treatment to those patients who need it. As an example, a cost-effectiveness study conducted in Japan in 2014 by Okubo et al showed good cost-effectiveness concerning the active screening of OSA in middle-aged men with diabetes or chronic kidney disease (CKD), and that led the authors to suggest the introduction of OSA screening in the guidelines for diabetes and CKD. ${ }^{25}$

\section{CONCLUSION}

The results of this study suggest that, even though obesity is recognized as one of the major risk factors for OSA, the underdiagnosis of OSA in obese individuals may be very high and that many may even present a risk of unrecognized moderate to severe disease. Consequently, these patients may end up not receiving treatment, with implications in morbidity and mortality due to cardiovascular diseases closely related to OSA.

The real prevalence of OSA in Portugal is unknown, so there is a need to extend the study of the risk of undiagnosed OSA to other at-risk groups, as well to carry out cost-effectiveness studies that may be useful for the development of clinical guidelines which allow the reduction of the underdiagnosis and providing treatment to patients with OSA.

The magnitude of this disease should be present in the minds of PHC doctors who may represent an essential pillar in the reduction of underdiagnosis, especially in the major risk groups, such as obese individuals. 


\section{PROTECTION OF HUMANS AND ANIMALS}

All procedures performed in the study were in accordance with the ethical standards of the institutional and national research committee (Ethics Committee of the Portuguese Regional Health Administration of the North (ARS Norte)) and with the 1964 Helsinki declaration and its later amendments or comparable ethical standards.

\section{INFORMED CONSENT}

Informed consent was obtained from all individual participants included in the study.

\section{REFERENCES}

1. Costa C, Santos B, Severino D, Cabanelas N, Peres M, Monteiro I, et al. Obstructive sleep apnea syndrome: an important piece in the puzzle of cardiovascular risk factors. Clin Investig Arterioscler, 2015;27:256-63.

2. Senaratna C, Perret J, Lodge C, Lowe A, Campbell B, Matheson M, et al. Prevalence of obstructive sleep apnea in the general population: a systematic review. Sleep Med Rev. 2017;34:70-81.

3. Peppard P, Young T, Barnet J, Palta M, Hagen E, Hla K. Increased prevalence of sleep-disordered breathing in adults. Am J Epidemiol. 2013;177:1006-14

4. Heinzer R, Vat S, Marques-Vidal P, Marti-Soler H, Andries D, Tobback $\mathrm{N}$, et al. Prevalence of sleep-disordered breathing in the general population: the HypnoLaus study. Lancet Respir Med. 2015;3:310-18.

5. Watson N. Health care savings: the economic value of diagnostic and therapeutic care for obstructive sleep apnea. J Clin Sleep Med. 2016;12:1075-7.

6. Olaithe M, Bucks R, Hillman D, Eastwood P. Cognitive deficits in obstructive sleep apnea: Insights from a meta-review and comparison with deficits observed in COPD, insomnia, and sleep deprivation. Sleep Med Rev. 2018; 38:39-49.

7. Jordan A, McSharry D, Malhotra A. Adult obstructive sleep apnoea. Lancet. 2014;383:736-47.

8. Jennum P, Riha R. Epidemiology of sleep apnoea/hypopnoea syndrome and sleep-disordered breathing. Eur Respir J. 2009;33:907-14

9. Chung F, Abdullah H, Liao P. STOP-Bang Questionnaire: a practical approach to screen for obstructive sleep apnea. Chest. 2016;149:631-8.

10. Rebelo-Marques A, Vicente C, Valentim B, Agostinho M, Pereira R, Teixeira M. STOP-Bang questionnaire: the validation of a Portuguese version as a screening tool for obstructive sleep apnea (OSA) in primary care. Sleep Breath. 2018;22:757-65.

11. Rodrigues A, Pinto P, Nunes B, Barbara C. Obstructive sleep apnea: epidemiology and Portuguese patients profile. Rev Port Pneumol (2006). 2017;23:57-61.

12. Young T, Skatrud J, Peppard P. Risk factors for obstructive sleep apnea in adults. JAMA. 2004;291:2013-6.

13. Drager L, Lopes H, Maki-Nunes C, Trombetta I, Toschi-Dias E, Alves M, et al. Obstructive sleep apnea: a cardiometabolic risk in obesity and the metabolic syndrome. J Am Coll Cardiol. 2013;62:569-76.

14. Bauters F, Rietzschel E, Hertegonne K, Chirinos J. The link between

\section{CONFLICTS OF INTEREST}

The authors have declared that no competing interests exist.

\section{FUNDING SOURCES}

This research received no specific grant from any funding agency in the public, commercial, or not-for-profit sectors.

obstructive sleep apnea and cardiovascular disease. Curr Atheroscler Rep. 2016;18:1.

15. Chung F, Yang Y, Liao P. Predictive performance of the STOP-Bang score for identifying obstructive sleep apnea in obese patients. Obes Surg. 2013;23:2050-7.

16. Chiu H, Chen P, Chuang L, Chen N, Tu Y, Hsieh Y, et al. Diagnostic accuracy of the Berlin questionnaire, STOP-BANG, STOP, and Epworth sleepiness scale in detecting obstructive sleep apnea: a bivariate metaanalysis. Sleep Med Rev. 2017;36:57-70.

17. El-Sayed I. Comparison of four sleep questionnaires for screening obstructive sleep apnea. Egyptian J Chest Dis Tubercul. 2012;61:43341.

18. Reis R, Teixeira F, Martins V, Sousa L, Batata L, Santos C, et al., Validation of a Portuguese version of the STOP-Bang questionnaire as a screening tool for obstructive sleep apnea: analysis in a sleep clinic. Rev Port Pneumol. 2015;21:61-8.

19. Oliveira A, Araujo J, Severo M, Correia D, Ramos E, Torres D. Prevalence of general and abdominal obesity in Portugal: comprehensive results from the National Food, nutrition and physical activity survey 2015-2016. BMC Public Health. 2018;18:614

20. NCD Risk Factor Collaboration. (NCD-RiscC) Trends in adult body-mass index in 200 countries from 1975 to 2014: a pooled analysis of 1698 population-based measurement studies with $19 \cdot 2$ million participants. Lancet. 2016;387:1377-96

21. Nagappa M, Liao P, Wong J, Auckley D, Ramachandran S, Memtsoudis $\mathrm{S}$, et al. Validation of the STOP-Bang Questionnaire as a screening tool for obstructive sleep apnea among different populations: a systematic review and meta-analysis. PLoS One. 2015;10: e0143697.

22. Miller J, Berger A. Screening and assessment for obstructive sleep apnea in primary care. Sleep Med Rev. 2016;29:41-51.

23. Bailes S, Baltzan M, Rizzo D, Fichten C, Grad R, Wolkove N, et al., Sleep disorder symptoms are common and unspoken in Canadian general practice. Fam Pract. 2009;26:294-300.

24. Ramachandran SK, Josephs LA. A meta-analysis of clinical screening tests for obstructive sleep apnea. Anesthesiology. 2009;110:928-39.

25. Okubo R, Kondo M, Hoshi S, Yamagata K. Cost-effectiveness of obstructive sleep apnea screening for patients with diabetes or chronic kidney disease. Sleep Breath. 2015;19:1081-92. 